\title{
The psychological dimension of organ transplant patients: Mini review
}

\author{
Ginevra Di Matteo**, Angela De Figlio and Tiziana Pietrangelo** \\ Department of Neuroscience, Imaging and Clinical Sciences, “G. D’Annunzio University, Chieti-Italy \\ \#Contributed equally
}

\begin{abstract}
The aim of this report is to analyze the psychological dimension and the quality of life in patients with organ transplants. The protagonist of the entire transplantation process is the recipient. The recipient is a person, with feelings, personal values, social and working interests, and sometimes suffering psychopathological symptoms from the stress of the illness and the impending danger. These factors must all be considered and treated in order to achieve a successful treatment. It should be noted that along with the improvements in organ transplants, there has been a significant increase in the changes that the therapies cause; for example, physical, emotional and social effects, which trigger psychological changes in the exposed patient, such as self-image, personal frame of mind, family behavior, sex, and social mood. These issues need to be addressed from time to time by initiating personalized assistance programs. In the Biopsychosocial Model, the transplant experience brings together the body-mind-body relationship. The holistic principle of this model involves a health concept based on harmony between the body, the psyche and the outside world.
\end{abstract}

\section{Introduction}

Organ transplantation is a surgical procedure consisting of taking an organ from a healthy donor and transplanting it into a recipient patient. Deceased donors can provide: skin, cornea, bone marrow, kidney, heart, lungs, liver, pancreas, and gastrointestinal tract. Living donors can provide partial kidneys or liver. The transplantation of organs in humans began about 1900. It embodied a previously forbidden idea, and a secret dream cherished by doctors, physiologists and anatomists for centuries.

The transplant is an operation with important psychological implications, especially for major organs. The more the organ is symbolically important, the more it brings out psychologically important fantasies, with repercussions on prognosis. While some find a way to integrate the organ into their new life and their new body, others never succeed completely.

The "Golden Legend" of Jacopo de Voragine (1228-1298) recounts the miracle of Saints Cosmas and Damian [1], who appeared in a dream to the deacon of the basilica of Santa Maria Maggiore in Rome. They cut off his gangrenous leg, replacing it with one taken from the corpse of an Ethiopian. The first heart and kidney transplants were carried out on animals in the early 1900s by connecting veins and arteries, using a technique developed by Alexis Carrel [2]. Why transplanted organs were fatally rejected by recipients was unknown at first. About 1940, Medawar [3] discovered that genetic differences between donors and recipients caused the rejection of tissue implanted in severely burned patients. In 1954, Murray [4] performed the first successful kidney transplant between identical twins. After the mechanism of rejection became clear and procedures were developed to overcome it, transplants were extended to other organs. In 1963, Starzl [5] performed the first liver transplant, and Hardy successfully transplanted the first lung. In 1966, Kelly and Lillehei [6] conducted the first pancreas transplant. In 1967, Barnard [7] performed the first heart transplant. For many seriously ill people, a transplant is the only therapeutic option that can offer a life expectancy and quality of life close to normal. In many cases, it is the only way to escape a premature death.

Today, scientific research has achieved significant success. While the procedure at first only guaranteed the survival of the organ and the patient, today, we can expect full physical, mental and social recovery of a person who undergoes organ transplantation [8]. Research into short- and long-term effects of transplantation [9] revealed an overall improvement in quality of life before and after transplantation, and a better quality of life for transplant patients than for other patients.

The protagonist of the entire transplantation process is the recipient and the recipient's family. The recipient is a person, with feelings, personal values, social and working interests, and sometimes suffering psychopathological symptoms from the stress of the illness and the impending danger. These factors must all be considered and treated in order to achieve a successful treatment.

Therapeutic design in organ transplantation includes aspects closely related to the subjective and psychological risk: from the quality of life in patients with transplants to the ethical and personal problems of the donors; from psychological support to the families of both donors and recipients to staff training in the intensive care unit; and the delicate aspects of pediatric transplants.

${ }^{\star}$ Correspondence to: Tiziana Pietrangelo, Associate Professor in Physiology, Department Neuroscience Imaging and Clinical Sciences, "G. D'Annunzio" University, via dei Vestini 31, Chieti, Italy, E-mail: tiziana.pietrangelo@unich.it

Ginevra Di Matteo, Master's Degrees in Psychology, “G. D’Annunzio” University, via dei Vestini 31, Chieti, Italy, E-mail: ginevraitaly@hotmail.com

Key words: organ transplantation, psychological dimension, quality of life

Received: August 25, 2018; Accepted: August 31, 2018; Published: September 04, 2018 
It should be noted that along with the improvements in organ transplants, there has been a significant increase in the changes that the therapies cause; for example, physical, emotional and social effects, which trigger psychological changes in the exposed patient, such as self-image, personal frame of mind, family behavior, sex, and social mood. These issues need to be addressed from time to time by initiating personalized assistance programs.

In the Biopsychosocial Model [10], the transplant experience brings together the body-mind-body relationship. The holistic principle of this model involves a health concept based on harmony between the body, the psyche and the outside world. During the transplant period, the balance between the parties is threatened by major emotional and psychological distress, because often the experience is connected to:

- sensing the loss of a body part,

- sensing the possibility of death,

- changes in diet,

- physical complications,

- pharmacological side effects,

- anxiety and depression,

- sexual problems,

- second thoughts about workplace, family, and social roles.

\section{Pre-transplant}

Psychological and psychiatric counseling during pre-transplant meetings with the patient and family must delicately achieve a selective assessment, and objectively analyze the cognitive, emotional and relational state of the patients involved. This is needed to establish their suitability for a transplant. This goal is pursued by planning a rehabilitation program early on, which takes into account the needs, resources and limitations of each patient, and which promptly identifies problems that could compromise the outcome of the therapy.

The cognitive-affective assessment is performed by administering psycho-diagnostic tests, such as the CBA 2.0 (Cognitive Behavioral Assessment) [11], the Generalized Self Efficacy Test [12], and the SF36 (Short Form 36) [13], a questionnaire about the patient's health and possibly Projective Tests such as the TAT (Thematic Apperception Test) [14], the Tree Test [15], the Family Drawing test [16], the Human Figure drawing test [17], the Wartegg Test [18], the Rorschach Test [19], and the MMPI-2 [20]. These tests highlight knowledge of personality dynamics, self-representation, investigate the bodily experience with respect to surroundings, past and present family ties and various conflicts among members. They also investigate cognitive, affective and emotional personality [21].

Anxiety is an ever-present state that rarely takes the form of a panic attack. It mainly results in psychological disorders such as insomnia, worries of a hypochondriac nature and of phobic-obsessive manifestations.

Dew, et al. reported major depressive episodes in $17 \%$ of cases of heart transplant patients, other post-traumatic stress disorder in $13 \%$ of the cases, and adjustment disorder [22] in 10\%. The latter often resulted in cognitive and attentional difficulties, with a general restriction of activity and/or abandoning personal plans. Only in extreme cases were there delirious manifestations and psychotic syndromes.
The following are considered absolute psychiatric contraindications for transplantation: severe mental disorders such as florid psychosis, severe mental retardation, substance/alcohol dependence or abuse, active suicidal thoughts, high risk-behavior, and therapeutic noncompliance $[23,24]$.

Transplant success was defined by patients as a "honeymoon" [25]. This sense of well-being was particularly evident in heart transplant patients, for whom the threat of death that characterized the pretransplant phase is gone, and symptoms such as angina and shortness of breath disappear.

\section{Post-transplant}

Transplant surgery always carries with it an emotional graft, also. The adaptation period after a transplant can last from six months to one year. According to Castelnuovo-Tedesco [26], during that time there is a succession of three phases:

- The "foreign body" phase: the transplanted organ can feel like a stranger to one's own body. This can give rise to persecution anxiety on one hand, or idealization on the other hand. It can be seen as a fragile and precious object, causing excessively protective feelings about it.

- The "partial incorporation" phase: the patient begins to integrate the organ.

- The "total incorporation" phase: the transplant is so completely acquired that the patient is no longer aware of it.

Surgery is a shock to the body, but it does force the Self to "rediscover the sense," sometimes through irrational representations and anxiety, and to mobilize the most archaic defense mechanisms:

- denial: to avoid ideas of death and mutilation;

- reactive formation, projective identification, and projection vis-ávis aggressiveness, which dependence on the donor understandably evokes;

- rationalization and intellectualization: to remove the anxietyprovoking affective load.

Health institutions should aim to provide valid psychological and social rehabilitation programs for transplant patients, that is, to normalize the transplanted patient's existence in order to help overcome the post-surgical shock, the side effects of anti-rejection therapies (tremors, cyclosporine-induced ataxia, cortisone-induced psycolability), the emotional crises caused by complications along the way, breakdown, and anger.

The clinical literature notes the difficulty that patients face returning to a "normal" life, because the implant involves all the aspects of a patient's life.

In a study of twenty-six couples, Bunzel showed that the impact of a heart transplant reflected negatively on a couple's domestic relationship. [27].

Hart, et al. showed that sexual dysfunctions of organ and psychic origin occurred in $25 \%$ to $40 \%$ of cases [28].

Antonucci, et al. noted that erectile dysfunction in the last stage of chronic renal failure continues to have a high prevalence in both patients on dialysis and those who received a transplant [29].

Nôtová, et al. showed that, on a social and working level, return to full employment occurred at an average of about $45 \%$, well below the average number who recovered physically [30]. 


\section{Body-image}

Human beings have mental representations of their bodies, and this is only partly innate. The representation is formed in early childhood, changes throughout life under conditions of health and disease. The body, therefore, is a nuanced and complex mental construction.

According to Schilder [31], disease in the organs is a key factor in the development and organization of the body. The disease of an organ is connected to a particular psychic condition. The feelings that arise affect directly the attitude and the general experience of the patient. This leads to a psychosomatic crisis, in which the somatic and the psychic aspects influence each other equally.

The success of the transplant depends on immunological compatibility. When this is not high, the transplant fails, causing rejection. At the same time, the Self must integrate the new organ, helping it to be functional and not dangerous and alien. The loss of the integrity of one's body image is a major psychological gap caused by the transplant. The path to restoring one's full identity is long and difficult, requiring the recovery of a whole body image $[32,33]$.

In some cases, psychic integration is not restored, and the patient continues to perceive the organ as foreign. Feelings of persecution by the organ may develop, creating confusion in the body image. This can push the patients toward an improper psychic compensation, requiring integrated and intensive psychological treatment. In the worst case, the psychological factors may induce the onset or intensification of the biological processes that cause rejection.

\section{Quality of life}

According to the World Health Organization (WHO), quality of life is "the perception that individuals have of their life, in the context of the culture and value system in which they live and in relation to their goals, expectations, reference standards and interests.

Politi, et al. showed that heart transplantation can lead to a high quality of life even ten years after surgery [34]. In this regard, the occurrence of anxiety-depressive disorders may play an important role. Buendia, et al. indeed demonstrated a correlation between depressive symptoms and low perceived quality of life [35]. For Grady and Lanuza [36], despite patients being satisfied with their quality of life, improving the physical capacity did not lead to normal values recorded by healthy subjects of the same age. To date, research continues to highlight the drastic improvement of the physical conditions in heart, lung and liver transplant patients. Out of 215 heart transplant patients, $75 \%$ identified the main benefit of the transplant as "to start a new life" [37].

The primary objective of health workers must be to lift the standards for quality of life, from the moment that a patient applies to receive a new organ.

\section{Conclusions}

We must move from a medical and clinical concept to a clinical and humanistic concept of health. This will help us consider the patient as a complex human being with a unique psychological, social and environmental history. A holistic view of health would merge the medical and psychological treatment to support the recipient throughout the entire journey to a "new life". It is not enough merely to try to safeguard health; it must be pursued proactively every day.

\section{Acknowledgments}

Thanks to Jonathan Hine for the English revision.

\section{References}

1. Lippi D (2009) The transplant of the white man's leg: a novel representation of Cosma and Damians miracle. Int J Immunopathol Pharmacol 22: 517-520. [Crossref]

2. Facchin C (1991) Alexis Carrel, tra scienza e vangelo il futuro dell'uomo, San Pietro in Cariano, Il Segno.

3. The Nobel Prize in Physiology or Medicine 1960 was awarded jointly to Sir Frank Macfarlane Burnet and Peter Brian Medawar "for discovery of acquired immunological tolerance", nobelprize.org

4. Murray JE (2001) Surgery of the Soul: Reflections on a Curious Career. Science History Publications, Watson Publishing International, Sagamore, MA.

5. Starzl TE (1993) Ai limiti del possibile, Memorie di un chirurgo dei trapianti, Longanes \& C., Edizione italiana a cura di Luigi Rainero Fassati Milano pp: 9-11.

6. Lillehei RC, Idezuki Y, Feemster JA, Dietzman RH, Kelly WD, et al. (1967) Transplantation of stomach, intestine, and pancreas: experimental and clinical observations. Surgery 62: 721-741. [Crossref]

7. Barnard CN (1967) A human Cardiac transplant: an interim report of a successful operation performed at Groote Schuur Hospital, Cape Town. S Afr Med J 41: 1271-1274.

8. Bravata DM, Olkin I, Barnato AE, Keeffe EB, Owens DK (1999) Health-related quality of life after liver transplantation: a meta-analysis. Liver Transpl Surg 5: 318-331.

9. Beilby S, Moss-Morris R, Painter L (2003) Quality of life before and after heart, lung and liver transplantation. $N Z$ Med J 116: U381. [Crossref]

10. Engel GL (1977) The need for a new medical model. A challenge for biomedicine. Science 196: 129-136

11. Bartolotti P, Michielin E, Sanavio G, Simonetti G, Vidotto AM, et al. (1987) “Cognitive Behavioural Assessment" Organizzazioni Speciali Firenze.

12. Bandura A (1977) Self-efficacy: Toward a unifying theory of behavioral change. Psychological Review 84: 191-215.

13. Ware JE Jr, Sherbourne CD (1992) The MOS 36-item short-form health survey (SF36). I. Conceptual framework and item selection. Med Care 30: 473-83.

14. Morgan ChD, Murray HA (1935) A method for investigating fantasies: The Thematic Apperception Test. Arch NeurPsych 34: 289-306

15. Koch K (1949) "Der Baumtest” (The Tree Test).

16. Corman L (1970) "Il disegno della famiglia: test per bambini”, Bollati Boringhieri, Torino.

17. Machover K (2010) “Test della figura umana” OS Giunti (2010) Firenze.

18. Wartegg E (1971) Wartegg-Erzählungs-Test. Hogrefe.

19. Rorschach H (1981) Psicodiagnostica, Roma, Edizioni Kappa.

20. Butcher JN, Graham JR, Ben-Porath YS, Tellegen A, Dahlstrom WG, and Kaemmer B Coordinator for the Press 1995-2011 MMPI $\mathbb{R}$-2 (Minnesota Multiphasic Personality Inventory $(2)$.

21. Olbrisch ME, Benedict SM, Ashe K, Levenson JL (2002) Jun Psychological assessment and care of organ transplant patients. J Consult Clin Psychol 70: 771-783.

22. Dew MA, Roth LH, Schulberg HC, Simmons RG, Kormos RL, et al. (1996) Prevalence and predictors of depression and anxiety-related disorders during the year after heart transplantation. Gen Hosp Psychiatry 18: 48S-61S

23. Rupolo G, Poznanski C (1999) Psicologia e psichiatria del trapianto d'organi. Masson, Milano.

24. Chacko RC, Harper RG, Gotto J, Young G (1996) Psychiatric interview and psychometric predictors of cardiac transplant survival. Am J Psychiatry 153: 16071612.

25. Christopherson LK (1987) Cardiac transplantation: a psychological perspective. Circulation 75: 57-62.

26. Castelnuovo TP (1981) "Transplantation: psychological implications of changes in body image" in Psychonephrology Psychological factors in hemodialysis and trasplantion Levy (Ed). Plenum Press, New York.

27. Bunzel B, Laederach-Hofmann K, Schubert MT (1999) Patients benefit-partners suffer? The impact of heart transplantation on the partner relationship. Transpl Int 12: 33-41.

28. Hart LK, Milde FK, Zehr PS, Cox DM, Tarara DT, et al. (1997) Survey of sexual concerns among organ transplant recipients. J Transpl Coord 7: 82-87. 
29. Antonucci M, Palermo G, Recupero SM, Bientinesi R, Presicce F, et al. (2016) Male sexual dysfunction in patients with chronic end-stage renal insufficiency and in renal transplant recipients. Arch Ital Urol Androl 87: 299-305.

30. Nôtová P, Schreinerová Z, Schrameková E, Bass K, Fabián J (1997) Quality of life after heart transplantation--psychosocial aspects. Bratisl Lek Listy 98: 278-283.

31. Shilder P (1935) Image and appearance of the human body. London, Kegan, Trench.

32. Zimbrean PC (2015) Body image in transplant recipients and living organ donors. Curr Opin Organ Transplant 20: 198-210. [Crossref]

33. Kugler C, Geyer S, Gottlieb J, Simon A, Haverich A, et al. (2009) Symptom experience after solid organ transplantation. $J$ Psychosom Res 66: 101-110.
34. Politi P, Piccinelli M, Poli PF, Klersy C, Campana C, et al. (2004) Ten years of "extended" life: quality of life among heart transplantation survivors. Transplantation 78: 257-263.

35. Buendía F, Almenar L, Martínez-Dolz L, Sánchez-Lázaro I, Navarro J, et al. (2011) Relationship between functional capacity and quality of life in heart transplant patients. Transplant Proc 43: 2251-2252.

36. Grady KL, Lanuza DM (2005) Physical Functional Outcomes after Cardiothoracic Transplantation. $J$ Cardiovasc Nurs 20: s43-s50.

37. Pellegrini A, Colombo T. Quaini E (1994) Qualità di vita dopo il trapianto cardiaco. In: Cardiologia. Atti del 28. Convegno Internazionale del Centro A. De Gasperis. Milano 26-30 settembre. Scientific Press, Milano. pp: 41-47.

Copyright: $@ 2018$ Di Matteo G. This is an open-access article distributed under the terms of the Creative Commons Attribution License, which permits unrestricted use, distribution, and reproduction in any medium, provided the original author and source are credited. 